\title{
Hyaluronidase and sodium hyaluronate in cataract surgery
}

\author{
I G CALDER AND V H SMITH
}

From the Birmingham and Midland Eye Hospital

SUMmARY The use of sodium hyaluronate in cataract surgery and intraocular lens implantation is often followed by a postoperative rise of intraocular pressure. A trial is described in which 10 patients underwent bilateral cataract extraction and Binkhorst intraocular lens implantation with the use of sodium hyaluronate. The enzyme hyaluronidase was instilled into the anterior chamber of the right eye only, to aid removal of sodium hyaluronate, and resulted in a statistically significant lowering of postoperative intraocular pressure in right eyes compared with left. Other uses of the enzyme are discussed.

Sodium hyaluronate $(\mathrm{SH})$ is a viscoelastic material which has found use in many anterior segment and some posterior segment surgical procedures. It has been widely investigated and reported on..$^{1-3}$ When it has been used as an aid to intraocular lens (IOL) implantation, a sharp rise in intraocular pressure (IOP) in the first three postoperative days has been noted ${ }^{34}$ over and above that originally reported by Rich and colleagues following cataract surgery before the advent of SH. ${ }^{S-7}$

Various techniques have been advocated to reduce this additional postoperative hypertension, including: (1) postoperative acetazolamide ${ }^{2}$; (2) postoperative timolol drops ${ }^{2}$; (3) intravenous mannitol, postoperatively and at the time of surgery ${ }^{3}$; (4) anterior chamber irrigation with balanced salt solution $^{13}$; (5) aspiration of $\mathrm{SH}$ with a wide-bore needle or Cavitron suction. ${ }^{3+}$

There are disadvantages and potential problems with all five of these methods. The postoperative remedies are often ineffective and/or slow to take effect,' and at times toxic to the patient. ${ }^{3}$ Berson $e t$ al. ${ }^{\mathrm{x}}$ demonstrated a substantial decrease in measured aqueous outflow facility following instillation of $\mathrm{SH}$ into the anterior chamber of enucleated human eyes. Acetazolamide, timolol, and intravenous mannitol are aimed at reducing the hypertensive effect of $\mathrm{SH}$ in the anterior chamber only after this outflow obstruction has occurred.

After IOL implantation $\mathrm{SH}$ can be irrigated out of the anterior chamber with balanced salt solution or

Correspondence to Mr I G Calder, Coventry and Warwickshire Hospital, Stoncy Stanton Road, Coventry CV1 4FH. aspirated with a wide-bore needle or by Cavitron suction..$^{13}$ In the study by Berson et al. ${ }^{8}$ irrigation of the anterior chamber with saline solution had only limited success in alleviating obstruction to outflow, and, while these methods may have clinical applications, their use following implantation of an anterior chamber iris clip lens may be hazardous. Sudden expulsion or aspiration, from a partly open section, of a large volume of SH could result in loss of anterior chamber depth and lens-endothelial contact or even vitreous loss. Yet SH offers such significant advantages in anterior/posterior segment surgery that any endeavours to reduce its unwanted postoperative side effects while retaining its surgical advantages would be welcome.

Hyaluronidase is an enzyme which cleaves $\mathrm{SH}$ into smaller fragments, and has been used experimentally in cadaver human eyes ${ }^{x}$ to degrade SH enzymatically, with dramatic results in reducing the hypertension following $\mathrm{SH}$ instillation. A reduction in trabecular meshwork obstruction and an increase in aqueous outflow facility was shown. Linn and Ozment reported some 35 years ago ${ }^{4}$ that the use of hyaluronidase was followed by a marked intraocular inflammatory reaction and suggested a potential risk to the corneal stroma. This was the result of the use of an enzyme containing impurities, but a highly purified enzyme is now available.

Our pilot studies showed that the instillation of hyaluronidase during intracapsular cataract extraction and IOL implantation, after the introduction of $\mathrm{SH}$, reduced the expected postoperative hypertension and allowed the egress of $\mathrm{SH}$ from the 
anterior chamber in a controlled manner. The use of the enzyme in cataract surgery has been mentioned previously, ${ }^{3}$ but without the results of a clinical trial.

We describe a trial of the use of hyaluronidase to remove SH from the anterior chamber after intracapsular cataract extraction and Binkhorst IOL implantation.

\section{Materials and methods}

Ten consecutive patients underwent uncomplicated bilateral intracapsular cataract extraction with insertion of Binkhorst (Cilco) iris clip IOLs. In all cases the operation was bilateral under the one general anaesthetic. The average age of the patients was 76 years, range 56 to 85 years.

All cases had preoperative endothelial cell counts by specular microscope photography with the HeyerSchulte microscope system. The surgery was carried out by the two authors under general anaesthesia. One surgeon performed both operations on a particular patient using an identical procedure for each eye. The choice of which eye was operated on first depended on which side the assistant's microscope was found to be at the start of surgery. This ensured a random selection beyond the surgeon's control. An ab externo approach, under a limbal-based conjunctival flap, was employed. Two peripheral iridectomies were performed, followed by instillation of $\alpha$ chymotrypsin and a cryoextraction of the lens. SH was then used to form the anterior chamber, and to coat the IOL, which was secured, after placement, with a $10 / 0$ nylon iris suture. Miochol (acetylcholine $1 \%$, mannitol $3 \%$ ) was instilled. The wound was closed with at least nine $8 / 0$ virgin silk sutures; $0.5 \mathrm{ml}$ of hyaluronidase made up by dissolving 1500 units in $1 \mathrm{ml}$ of sterile water was then instilled at intervals into the anterior chamber, through the secured wound, of the right eyes only. One drop of topical $4 \%$ pilocarpine and a subconjunctival injection of methylprednisolone (Depomedrone) completed the procedure.

Postoperatively the IOP was measured daily from the first day until discharge, usually on the sixth postoperative day, and on each outpatient visit, by members of staff other than the authors. Postoperative medication consisted of a topical steroidantibiotic combination four times per day. If the IOP was above $30 \mathrm{mmHg}$ in either eye, systemic acetazolamide was added, and withdrawn as the pressure

Table 1 Average percentage endothelial loss

\begin{tabular}{lr}
\hline Right eye & $10 \cdot 25$ \\
Left eye & $8 \cdot 25$ \\
\hline
\end{tabular}

By the same statistical analysis there was no significant difference. came down. Endothelial cell counts were repeated on average four months postoperatively, with a range from $2 \frac{1}{2}$ to 6 months.

\section{Results}

The results are summarised in Tables 1,2 . Statistical analysis by the Wilcoxon matched-pairs signed-ranks test indicated a significant difference between IOP levels in the right and left eyes on days 1 and 2, but the significance was reduced on day 3 . Preoperatively and by day 6 there was no significant difference.

\section{Discussion}

The postoperative rise in IOP which may occur after cataract surgery has been extensively studied by Rich and colleagues ${ }^{s-7}$ among others. Many workers have reported on the postoperative ocular hypertension following the use of SH. ${ }^{1-1}$ It was in an attempt to reduce this pressure rise that the enzyme hyaluronidase was used to aid in the safe removal of SH from the anterior chamber.

Apart from case 1 , in which the right eye showed a marked pigment dispersion in the anterior chamber, all cases showed a much lower postoperative IOP in the right eye than in the left on days 1 to 3 . By the sixth postoperative day this pressure difference had largely disappeared.

The intraocular levels postoperatively in the left eyes were higher than reported in some series, for example Percival," but this is a function of the comparatively large number of sutures used in an attempt to achieve watertight closure and to avoid wound rupture, which featured in the previously reported cases." Our postoperative intraocular pressure levels in the left eyes were similar to those found by Rich et al.'

The intraocular levels in the right eye were lower than that recorded by Rich et al. ${ }^{7}$ despite a similar

Table 2 Pre-and postoperative intraocular pressure levels

\begin{tabular}{|c|c|c|c|}
\hline & \multicolumn{2}{|c|}{$\begin{array}{l}\text { Mean of intraocular } \\
\text { pressures in } \mathrm{mmHg} \\
\text { (standard deviations in } \\
\text { brackcts) }\end{array}$} & \multirow[t]{2}{*}{$\begin{array}{l}\text { Level of } \\
\text { significance }\end{array}$} \\
\hline & Right & Left & \\
\hline $\begin{array}{l}\text { Preoperative } \\
\text { Postopcrative }\end{array}$ & $14 \cdot 5(2 \cdot 3)$ & $14 \cdot 2(2 \cdot 3)$ & \\
\hline Day 1 & $21 \cdot 3(6 \cdot 0)$ & $36 \cdot 1(9 \cdot 3)$ & $\mathrm{p}<() \cdot(\mathbf{)} 2$ \\
\hline Day 2 & $15 \cdot 3(5 \cdot 2)$ & $23 \cdot 7(6 \cdot 6)$ & $\mathrm{p}<0 .(0)$ \\
\hline Day 3 & $15 \cdot 5(8 \cdot 5)$ & $20 \cdot 6(7 \cdot 6)$ & $0.1>p>0.05$ \\
\hline Day 6 & $14 \cdot 3(5.9)$ & $14 \cdot 3(3 \cdot 2)$ & \\
\hline $2-4$ wecks & $14.6(2.7)$ & $15 \cdot 3(1 \cdot 7)$ & \\
\hline $2-3$ months & $14 \cdot 1(3 \cdot 0)$ & $15 \cdot()(3.6)$ & \\
\hline
\end{tabular}


technique, and this may be the result of a dual effect of hyaluronidase. As well as aiding in the removal of $\mathrm{SH}$ from the anterior chamber the enzyme may also have a direct effect on the trabecular meshwork, increasing outflow facility. Many workers, including Peterson and Jocson" and Knepper et al. ${ }^{12}$ have reported on the decreased outflow resistance which follows perfusion of the anterior chamber with hyaluronidase.

The final visual outcome was comparable in both groups, with the right eye achieving a marginally better standard. Apart from patient 10, who was known preoperatively to have bilateral disciform macular degeneration, the average visual outcome was $6 / 12$, with a range from $6 / 6$ to $5 / 60$. Two patients developed cystoid macular oedema; in both cases the left eye was more severely affected.

Postoperative endothelial cell counts indicated a comparable cell loss in the right and left eyes, and the percentage loss was in line with previously published results ${ }^{13}$ with the same instrument.

We thus suggest that instillation of hyaluronidase is a quick, easy, and safe method of reducing the postoperative ocular hypertension following cataract surgery involving $\mathrm{SH}$ and IOL implantation. The enzyme may well have other indications, for example, following anterior segment trauma, penetrating keratoplasty, or glaucoma surgery. In these situations $\mathrm{SH}$ is of value in maintaining tissue separation, but its presence can make it difficult to decide whether a wound is watertight or merely SHtight. This problem has been commented on by Roper-Hall. ${ }^{14}$

To use an agent that is known to cause a postoperative rise in IOP during glaucoma surgery is a questionable decision in spite of its manipulative advantages during surgery. If, however, the postoperative rise in IOP can be abated, many of the potential objections to its use are removed. Both trabeculectomy and goniotomy are particular examples, the first to restore the patency of the anterior chamber after decompression of the eye, the second to maintain a deep anterior chamber for the safe performance of the operation, in the knowledge that the SH can be completely removed and replaced by air to demonstrate its removal.

We are most grateful to Dr N Price for the specular microscopy; the Department of Hospital Statistics, Queen Elizabeth Hospital, Birmingham, for their advice on and help with the statistical analysis; and to Mrs C Rawlins for her secretarial help.

\section{References}

1 Miller D, Stcgmann R. Healon: a guide to its use in ophthalmic surgery. New York: Wilcy, 1983: 198.

2 Percival SPB. Complications from use of sodium hyaluronate (Healonid) in anterior segment surgery. Br J Ophthalmol 1982; 66: 714-6.

3 Emery JM, Jacobson AC. Current concepts in cataract surgery. New York: Appleton-Century-Crofts, 1982: 79-81.

4 Cherfan GM, Rich WJ, Wright G. Raised intraocular pressure and other problems with sodium hyaluronate and cataract surgery. Trans Ophthalmol Soc UK 1983; 103: 277-9.

5 Rich WJ. Intraocular pressure and wound closure after cataract extraction. Trans Ophthalmol Soc UK 1968; 88: 437-9.

6 Rich WJ. Further studies on early postoperative ocular hypertension following cataract extraction. Trans Ophthalmol Soc UK 1969; 89: 639-44.

7 Rich WJ, Radtke ND, Cohan BE. Early ocular hypertension after cataract extraction. Br J Ophthalmol 1974; 58: 725-31.

8 Berson FG, Patterson MM, Epstcin DL. Obstruction of aqueous outflow by sodium hyaluronate in enucleated eyes. Am J Ophthalmol 1983; 95: 668-72.

9 Linn JG, Ozment TL. Some effects of injection of hyaluronidase into the anterior chamber. Am J Ophthalmol 1950; 33: 33-42.

10 Percival SPB. Sodium hyaluronate in cataract and intraocular lens'surgery. Trans Ophthalmol Soc UK 1983; 103: 254-8.

11 Peterson WS, Jocson VL. Hyaluronidase effects on aqueous outflow resistance. Am J Ophthalmol 1974; 77: 573-7.

12 Knepper PA, Farbman AI, Tclser AG. Exogenous hyaluronidases and degradation hyaluronic acid in the rabbit eye. Invest Ophthalmol Vis Sci 1984; 25: 286-93.

13 Roper-Hall MJ, Wilson RS. Reduction in endothelial cell density following cataract surgery and intraocular lens implantation. Br J Ophthalmol 1982; 66: 516-7.

14 Roper-Hall MJ. Visco clastic materials in the surgery of ocular trauma. Trans Ophthalmol Soc UK 1983; 103: 274-6.

Accepted for publication 24 October 1985. 